\title{
POÉTICA DE LA DISGREGACIÓN BIOGRÁFICA Y DE LA OCULTACIÓN EN FRED CABEZA DE VACA DE VICENTE LUIS MORA
}

\author{
ANA CALVO ReVILla \\ Universidad San Pablo-CEU
}

\section{Resumen}

A través de la confluencia de escritura y teoría, del ensamblaje entre el placer estético y la epistemología textual y de una premeditada discontinuidad discursiva y fragmentaria, Fred Cabeza de Vaca es una obra comprometida con la literatura como instrumento de conocimiento de la contemporaneidad y de indagación distópica. La fragmentariedad es la estructura narratológica a través de la cual el escritor aborda la disolución del yo cartesiano y la incognoscibilidad de lo real y la expresión de la poética de la ocultación.

Palabras clave: falacia biográfica, biografema, estética fragmentaria, Fred Cabeza de Vaca, Vicente Luis Mora.

\section{POETICS OF THE BIOGRAPHICAL DISINTEGRATION AND CONCEALMENT IN FRED CABEZA DE VACA BY VICENTE LUIS MORA}

\section{Abstract}

Through the confluence of writing and theory, through the assembly between aesthetic pleasure and textual epistemology and through a deliberate discursive and fragmentary discontinuity, Fred Cabeza de Vaca is a work committed to literature as an instrument of knowledge of contemporaneity and dystopian inquiry. Fragmentation is the narratological structure through which the writer approaches the dissolution of the Cartesian self and the unknowability of what is real and it becomes a means of expressing the poetics of concealment.

Keywords: biographical fallacy, biographem, fragmentary aesthetic, Fred Cabeza de Vaca, Vicente Luis Mora. 


\section{FALACIA BIOGRÁFICA, FICCIONALIDAD Y DISOLUCIÓN GENÉRICA}

¿Qué pasa con el sujeto de la enunciación si se produce desde la dispersión a partir de anexiones no lineales bloqueando la serialización y la reconducción circular al origen? (Deleuze y Guattari, 1997: 13)

Estas palabras de Gilles Deleuze y Félix Guattari enmarcan Fred Cabeza de Vaca (Mora, 2017a), novela con la que Vicente Luis Mora obtuvo el Premio Torrente Ballester y en la que cristaliza en gran medida el pensamiento teórico-literario y artístico contemporáneo. A través de la vida de Fred, de sus ideas político-sociales, filosóficas o estéticas y de su poética, el autor establece un diálogo intelectual sobre el arte de la ficción. Aunque son muchas las tesis convocadas y las referencias que como en un tablero de ajedrez juegan a ser desplazadas de un lado a otro, podemos distinguir dos ejes configuradores: la desactivación del recurso a la ficción biográfica y la construcción de una metáfora apocalíptica sobre el arte contemporáneo (Alberca, 2017); centraremos nuestra atención en el primer aspecto.

Gracias al hallazgo del archivo del artista, un «archipiélago textual y documental» (Mora, 2017b), la profesora universitaria Natalia Santiago Fermi emprende la reconstrucción de la biografía póstuma del crítico y comisario de arte Fred Cabeza de Vaca (1980-2030), «uno de los mayores artistas que ha dado el mundo en el siglo XXI» (17) ${ }^{1} \mathrm{y}$ «Premio Nacional de Artes Plásticas» (115). Este hecho determina el complejo planteamiento narrativo de esta obra, que presenta cierta resistencia al análisis al tiempo que lo provoca, lo que permite que el lector y la crítica reflexionen sobre su significado y alcance.

Como ha puesto de relieve Manuel Alberca, Fred Cabeza de Vaca «contiene en su forma y en su contenido todos los elementos y protocolos de una biografía» (Alberca, 2017: 44); sin embargo, el autor empírico la desactiva en una nota preliminar, donde advierte al lector que se enfrenta a una creación textual ficticia:

ADVERTENCIA PREVIA, QUE A ESTAS ALTURAS DE LA EXISTENCIA DE LA ESPECIE HUMANA SOBRE LA TIERRA NO DEBERÍA SER NECESARIA, POR OBVIA Y DE

\footnotetext{
${ }^{1}$ A partir de este momento solo se hace referencia a la página en las citas y menciones a la obra analizada (Mora, 2017a).
} 
SENTIDO COMÚN, PERO QUE DEBE SER RECORDADA UNA VEZ MÁS, Y QUIZÁ CON MAYOR AHÍNCO QUE NUNCA, ANTE LOS PROFUSOS Y PAVOROSOS EJEMPLOS DE OLVIDO CONSTATABLES EN LOS ÚLTIMOS AÑOS, COINCIDENTES CON LA DESAPARICIÓN DE LA FORMACIÓN HUMANÍSTICA:

Esto es una ficción.

Era necesario que subrayara el escritor que no se está ante un simulacro, pues había demostrado con anterioridad su maestría y dominio en el hoax literario (Mora, 2010), donde inventó la escritura de un crítico inexistente y la de un ficticio escritor. Vicente Luis Mora advierte así a los lectores del riesgo de confundir la obra literaria con las circunstancias en que se escribió, como puso de relieve Wimsatt (1954). Y se anticipa a la tentación de quien pudiera basar las valoraciones críticas de la obra en las intenciones del autor, en su «querer decir»; condensa sintéticamente la tesis de la falacia intencional, la cual remite a la idea de que para acertar con el significado de la obra literaria se precisa entrar en la psicología del escritor; como a los teóricos del New Criticism, no ha de interesarle al crítico ni al biógrafo la intención del autor, pues ambos son conocedores de que puede mediar un abismo entre las pretensiones del artista y sus logros.

A continuación, la biógrafa ofrece en la sección «Introducción» un tablero de instrucciones, donde, siguiendo el modelo de Rayuela, dibuja su estructura laberíntica, subrayando que puede ser leída siguiendo diversos itinerarios. El resultado será semejante para el lector, pues se verá obligado a realizar una permanente búsqueda de orientación debida a la discontinuidad y fragmentariedad discursivas ${ }^{2}$.

${ }^{2}$ La fragmentariedad está presente en otras obras narrativas, como El batallón de los perdedores (2006), de Salvador Gutiérrez Solís; La conferencia. El plagio sostenible(2006), de Pepe Monteserín; El infierno(2007), de José Luis Gracia Mosteo; Click (2008), de Javier Moreno; Derrumbe (2008) y El corrector (2010), de Ricardo Menéndez Salmón; Naturaleza infiel (2008) de Cristina Grande; De música ligera (2009), de Aixa de la Cruz; Bilbao-New York-Bilbao (2009), de Kirmen Uribe; La nueva taxidermia (2011), de Mercedes Cebrián; De música ligera (2010), de Aixa de la Cruz; La mujer del Rapallo (2011), de Sònia Hernández; Barra americana (2011), de Javier García Rodríguez; Biblioteca Nacional (2012), de Mario Crespo; El váter de Onetti (2013), de Juan Tallón; Standards (2013), de Germán Sierra; Autopsia(2014), de Miguel Serrano Larraz; Viento de tramontana (2014), de Sergio Gaspar; Los últimos (2014), de Juan Carlos Márquez; etc. 
Salvo esta advertencia y la nota introductoria, una vez comenzada la obra despliega todo el artificio para ganarse el crédito de que los datos que se le ofrecen son documentos biográficos fidedignos. Pretende suscitar en el lector la adhesión a la veracidad de los hechos que conforman la trama y confundirlo con los recursos formales, temáticos, pragmáticos y epistemológicos propios de la biografía. Salvo ocasiones aisladas en las que la trama se plantea en el ámbito de la ciencia ficción, la realidad penetra tanto en la ficción que puede resultar complejo establecer los límites resbaladizos con que se opera en ambos planos. A pesar de la apariencia realista que revisten los documentos biográficos que se insertan en la obra, esto no permite trasladar el realismo al imaginario ficcional que Fred Cabeza de Vaca construye desde el inicio, pues la ficcionalidad no regula las relaciones entre obra-mundo, sino que es una estrategia pragmática que garantiza que la recepción de la obra se establece en dichos términos (Pozuelo Yvancos, 1993: 97-98).

Pretende la biógrafa escribir «la primera biografía seria, rigurosa y documentada del artista» (17), pues los intentos anteriores «que tendían más al escándalo morboso que al estudio integral y desapasionado de la persona vista desde su trabajo artístico y no al revés» se habían arruinado ante el rechazo de la crítica, según afirma en la nota introductoria (17). Sin embargo, Natalia no pudo culminar su proyecto debido no solo a la imposibilidad de descifrar el enigma que rodea al polémico y provocador personaje, sino también al caos que impera en la catalogación de sus documentos bajo claves alfanuméricas, según afirma Fred en una anotación de su diario:

Sin embargo, la urgencia en algunos casos, el olvido de las reglas en otros y querer salir del paso en la mayoría, pensando que era mejor guardar los archivos de cualquier forma que perderlos, me ha conducido a un maremágnum absoluto. Imagino la perplejidad que embriagaría a quien accediese a la carpeta de mis documentos ahora y se topase con cientos de archivos de títulos incomprensibles y contradictorios, de los que ni siquiera sé en ocasiones cuál es la última versión. La misma incertidumbre sufro yo, la verdad. Para ordenarlo todo habría que imprimir cada uno de ellos, leerlo, catalogarlo y nominarlo de nuevo (245-246).

Como sostiene el escritor en una anotación de su bitácora, la técnica del archivo / manuscrito encontrado resulta rentable a quienes, como él, 
«descreen del decimonónico narrador omnisciente» (Mora, 2008)3. Permanece así abierta la posibilidad de recombinar de manera diferente cada archivo y emprender la creación de un relato distinto que adquiera un nuevo significado.

Con gran libertad creativa se enfrenta Mora a un género literario que en la cultura española fue desdeñado por parte de los teóricos y críticos hasta la década de los noventa (Caballé, 1995; 2012: 39). Con la biografía falsa de un artista que nunca existió arma una novela sumamente compleja. Fred Cabeza de Vaca absorbe los diferentes grados de ficcionalidad que reviste el género biográfico, como la autobiografía, la biografía, la memoria, el diario, etc. y transgrede las normas constitutivas del género para hacer una defensa a ultranza de la libertad de la ficción. Lo condensa bien una máxima que Fred anota en su diario: «Donde no hay normas, hay espacio» (77) o estas otras palabras que escribe el artista tras la lectura de una entrevista al escritor argentino César Aira:

«Me encanta su faceta de libertad desatada y de locura. Los artistas plásticos han tomado la delantera a los escritores en ese vale todo creativo que está siempre al borde del timo. [...] El impulso de hacer algo cada vez más raro está propulsando el arte hasta divertidísimas cotas de creciente demencia». Así es. Pero un arte regido en exclusiva por la mesura, la prudencia o la contención tampoco me parecería estimulante. Si no se desequilibra y saca al espectador de quicio, es mero manierismo (200-201).

En este sentido se ha pronunciado el escritor: «Fred es la novela más libérrima y libertina que he escrito, y estoy satisfecho de haberla dejado crecer como si fuera un organismo vivo»(Mora, 2017b) ${ }^{4}$. Vicente Luis

${ }^{3}$ Uno de los mecanismos habituales para encubrir la ficcionalidad de la obra y subrayar la autenticidad histórica es el del manuscrito encontrado; lo encontramos en las novelas de caballerías, en Don Quijote de la Mancha, en La novela de la momia de Gautier, en «Manuscrito en una botella» de Poe, en Pepita Jiménez de Valera, en La familia de Pascual Duarte de Cela, en El nombre de la rosa de Eco, en el relato "El hechizado» de Francisco Ayala, etc. Véanse los estudios de García Gual (2002: 29-56) y Baquero Escudero (2007-2008).

${ }^{4}$ Vicente Luis Mora es un escritor prolífico; su obra atraviesa distintos géneros literarios. Junto al libro de relatos Subterráneos (2006), la novela en marcha Circular 07. Las afueras (2007) y el volumen de aforismos Nanomoralia (2016), ha publicado las novelas Alba Cromm (2010) y Centroeuropa (2020). Es autor de los poemarios Texto refundido de la ley del sueño (1999), Mester de ciberyía (2000), Nova (2003), Autobiografía. Novela de terror (2003), Construcción (2005), Tiempo(2009) y Serie (2015). Dentro de sus ensayos destacan La huida de la imaginación (2018), La cuarta persona del plural. 
Mora explora en Fred Cabeza de Vaca nuevas vías; junto a la vida de Fred, encontramos referencias a un arsenal de obras que son fruto de la imaginación del escritor. Como ficción ha de ser leída, sin pretender buscar correspondencias con las tesis del autor, aunque algunas de las reflexiones que en la obra se presentan hayan sido también objeto de reflexión para el teórico de la literatura. Iremos desgranando poco a poco este aspecto.

Son numerosas las ocasiones en las que Fred se presenta como autor de su autobiografía, en el sentido que Lejeune (1971: 14) daba al término; también es la persona responsable del contenido que vierte en sus apuntes y conversaciones y de la ordenación textual discursiva en la que va diseminando retazos de su vida. Lo refleja bien un comentario de Natalia:

Eckermann me ha aclarado en un correo electrónico que, si bien las entrevistas con Cabeza de Vaca fueron hechas en persona, el artista puso como condición sine qua non para sostener las conversaciones y publicarlas ulteriormente la de poder corregir y revisar sus textos antes de que fuesen entregados a la imprenta, lo que se hizo a mediados de mayo de $2030(59)$.

El ficticio artista da forma a través de la memoria a la narración retrospectiva de su existencia, haciendo hincapié en los acontecimientos que vertebran su mundo afectivo e itinerario profesional. Con su afición a la palabra artística deja múltiples huellas tanto de su fragmentada personalidad como de sus peripecias en el mundo del arte; pretende hacer creer al lector que toda su escritura se ratifica en el acto de verificación de su existencia y de los hechos que se narran.

En los «[Apuntes para memorias]» el protagonista deja registro sismográfico de su mundo interior sexual y afectivo, incluida la referencia al recuerdo infantil del coito entre sus padres (190-192): muestra su permisividad y desfachatez sexual, la pulsión incoercible de acudir a sex-

Antología de poesía española contemporánea (1978-2015) (2016), El sujeto boscoso. Tipologías subjetivas de la poesía española contemporánea entre el espejo y la notredad (1978-2015) (2016), La literatura egódica. El sujeto narrativo a través del espejo (2013), El lectoespectador (2012), Pasadizos. Espacios simbólicos entre arte y literatura (2008), La luz nueva. Singularidades en la narrativa española actual(2007), Pangea: Internet, blogs y comunicación en un mundo nuevo (2006), Singularidades: ética y poética de la literatura española actual (2006) y Autobiografía (novela de terror)(2003). 
shops (38) y a prostíbulos (31), o el fragor ruidoso y fecal de sus años universitarios madrileños (33-34); plasma los recuerdos asociados a Gabriela Háfiz Cote, mujer a la que amó y a la que nunca llamó por su nombre sino como 54 (247; 284); y los escarceos sofisticados y subversivos con otras mujeres $(59-61 ; 67-68 ; 82 ; 153-156)$, como deja constancia en esta anotación:

Lo que más me fascinaba de ella era su inaudita dimensión maléfica: era el mal mismo, disfrazada de pura bondad. Bajo su apariencia piadosa, serena y noble, casi beatífica, había cavernas de maldad, terceras dimensiones de vileza, mundos paralelos de malignidad infinita, y uno podía navegar y navegar durante horas y días y meses en esa infinitud perversa sin encontrar nunca un final; ella me enseñó que el horror no tiene horizonte y estuve fascinado durante eras en la variedad y vastedad de esos paisajes (127).

En estos apuntes memorísticos son menos frecuentes los que hacen referencia a la producción artística (143; 274-279); se ajustan en su mayoría a la recuperación de la historicidad del yo afectivo personal, sin que primen las referencias al tiempo histórico y sociocultural.

Bajo el paratexto "[Diario]» aparecen diseminadas las anotaciones que Fred toma a lo largo del tiempo, sin que parezca atisbar la significación última que pudieran entrañar; ayudan a «acercar el pasado al presente cuando se analizan con mirada retrospectiva» (Álvarez, 1989: 448). Hacen referencia a una gran diversidad de consideraciones filosóficas, que oscilan desde lo indescifrable del universo (34) o los estragos que el paso del tiempo deja en su cuerpo (63), hasta la última anotación que registra con fecha del 12/07/2030 para despedirse del mundo:

Es extraño despedirse de uno mismo. Decirse adiós. Hacerlo por escrito, para verlo, para poder creerlo. Me cuesta escribir. La mano me tiembla y apenas [ilegible] fuerzas.

Ni siquiera sé el sentido de redactar esto. Nadie va a leerlo. Pero dejo testimonio de que me dije adiós, eso es todo. Hay vidas que son [ilegible], otras que son viajes, y algunas pocas, más tristes como la mía, que son círculos. Acaban donde empiezan: alguien solo en un cuarto, contando que está en un cuarto a solas, escribiendo a oscuras, porque entiende demasiado tarde que sólo la ceguera es esencial. Te hice caso, Pascal, pero 
quizá debí seguir los consejos de Epicuro y no los tuyos. Ahora habría alguien a mi lado. En realidad, hoy seguiré el modelo vital de Sócrates. Soy una plaga que termina conmigo.

Bueno, Fred: adiós. Ha sido un placer. Veneno, haz tu trabajo. Y disolvámonos en silencio entre los átomos (307).

En estos apuntes del diario relata experiencias de naturaleza variada, como: la plaga desorbitada de hormigas africanas procedentes de Italia a España (94-95), la vivencia agobiante del espacio urbano (81-82), el impacto de los medios tecnológicos en la vida actual (261), o los peligros derivados del capitalismo: "Vivimos la tercera guerra mundial: el capital contra nosotros» (196); el irrealismo provocado "por la celeridad» que hace percibir la vida real «como un fotograma borroso» (106); la erotización de la existencia $(84 ; 194 ; 201 ; 204-205 ; 261 ; 271-272 ; 289-290 ; 304-$ 305) o la sobreactuación del mundo gastronómico, como en esta anotación genial:

Estuve a punto de fotografiar la estúpida carta que nos trajeron, pero pensé que ella podría considerarlo un gesto de mal gusto (a Pascal todo le parecía de mal gusto, o eso parecían decir las miradas compungidas que nos dedicaba a los presentes no galos), así que me dediqué a memorizar, mientras hablaban en francés de sus cachupinadas y pijerías, la descerebrada lista de platos que transparentaba las ínfulas humanísticas del chef: de primero había Verduras Sartreadas, Hojaldres de SalMichon (esto, como es obvio, es lo que encargó el chauvinista como entrante), EnlaSada Daniel, Coktail de Gambattista Vico (se olvidaron una i, los paramecios), Tartina de Nueces Borgeso y Sopa de Gideos (109).

No faltan reflexiones sobre los vínculos con el arte plástico (32) o el arte conceptual (76-77), los principios hobessianos imperantes en la narrativa televisiva seriada dominante (Lost, Utopia, The Wire, Fargo, The Leftlovers, etc.) (79), el afán desmedido de prestigio por parte de los críticos (83), o la relevancia de los silencios en la recepción de la creación artística (74-75):

Hoy hemos quedado para ir al cine. Le gusta escuchar las películas y odia las versiones audio-descritas de los deuvedés porque limitan su imaginación. Para ella las partes más interesantes de los filmes son los silencios, en los que puede estar pasando cualquier cosa en la pantalla. Ella 
imagina la escena y luego, según los sonidos a continuación, sabe si se ha acertado o construye un nuevo relato de acuerdo a lo escuchado. Es un proceso muy similar al de la creación, le he dicho y ha sonreído.

Los acontecimientos demandan del lector la aceptación como verdaderos, al margen de que provoquen adhesión o rechazo. Son numerosos los elementos (personas, acontecimientos, referencias a la contemporaneidad) que el autor extrae de la realidad e inserta en la narración al servicio de la verosimilitud, como la inclusión de documentación procedente de quienes conocieron al artista y escribieron o hablaron sobre él; y la incorporación al mundo ficcional de personalidades intelectuales, como el crítico Arthur C. Danto, el artista conceptual japonés On Kawara, el escritor argentino César Aira (200), el poeta y ensayista polaco Adam Zagajewski (193), los españoles Rafael Argullol, José Luis Brea (63), Miguel Ángel Hernández Navarro y Antonio Méndez Rubio (95), entre otros.

La novela busca la verosimilitud. Ofrece una prolífica documentación: discursos referenciales, recursos autobiográficos y mecanismos pragmáticos no-ficticios (diarios, memorias, cartas, catálogos de exposiciones, etc.); se aleja de la ambigüedad discursiva de la autoficción, con que el escritor suele reivindicar su presencia en la obra; y subraya de modos diversos su ficcionalidad, al tiempo que da cabida a la reflexión metaliteraria. Todos estos componentes contribuyen a la creación de un marco tan real que dificulta que el lector se enfrente a la narración desde una posición holgada. Y en este juego reta a la crítica a buscar el molde o marbete narrativo en el que pueda entroncar la novela. Presenta bajo la apariencia de un modelo de mundo I, que reproduce el mundo real efectivo, un modelo de mundo tipo II de lo ficcional verosímil (Albaladejo, 1992: 29). Las relaciones entre ficción-realidad o verosimilitud-ficción comprometen la estructura novelística y su forma arquitectónica.

\section{FICCIONALIDAD Y REFLEXIÓN METALITERARIA}

Con la premeditada discontinuidad discursiva y fragmentaria, el relato de la vida de Fred, lejos de ser un proyecto unitario y coherente, es la yuxtaposición de los distintos estratos (profesionales, sociales, familiares, etc.) que configuran una vida, a los que Mora intenta dar unidad desde una instancia narrativa externa: 
Esa compartimentación era casi obligatoria para contar una vida entera desde la perspectiva de una persona que está fuera, porque si uno cuenta su vida puede ficcionalizar la unidad del relato, pero cuando te asomas a la vida de una persona fallecida no puede haber unidad. Natalia cuenta a Fred, pero hubo mucha vida en la que ella no estuvo. Tanto Natalia como yo teníamos que salvaguardar la discontinuidad (Mora, 2017b).

Reúne Natalia S. Fermi esta información procedente de fuentes y materiales diversos (testimonios, cartas, diarios, artículos publicados, entrevistas, conversaciones etc.), con el fin de comprender mejor al biografiado. Si cualquier biógrafo se enfrenta siempre a la dificultad de la credibilidad, como deja constancia James Boswell en la primera edición de Life of Samuel Johnsonn, LL. D. (1791) $)^{5}$ Natalia también; y para salvar este problema procede con la meticulosidad de quien es consciente de la tarea que tiene por delante.

Como vemos, el material documental con el que trabaja la biógrafa es inmenso; así se deduce también de los artículos escritos por Fred (251259; 288-289); las Conversaciones con Eckermann, introducidas en unas ocasiones con autonomía textual (39-42; 56-59; 151-153; 163-165; 166 $169 ; 175-179 ; 308-309)$ y en otras, dentro de las reflexiones de Natalia (44-45); las entrevistas (73-74; 99-100) y grabaciones de Fred, como «[820hi5/24rich]» (91-92); las transcripciones de mesas redondas en las que participa el artista (95-96); los borradores de email (97-98; 100-102; 295; 295-296); sus obras inéditas (107); los fragmentos de podcast (127128) y de textos de Fred para catálogos (131-132; 293-295); los informes jurídicos (158-160); las anotaciones manuscritas de contenido erótico, como «[c126856.2025.9n5]» (185-187) y «[klñ.98.2025.n95]» (196-200), algunas sin datación cronológica (193-194; 318-319); las postales (195; 280); los extractos procedentes de entradas de blogs (201-202) y de la prensa (246), o los fragmentos de obras inventadas, como el ensayo

\footnotetext{
${ }^{5}$ Boswell (2007: 8): «Si tuviera que detallar los libros que he consultado y las indagaciones que me ha parecido necesario emprender, probablemente se me tendría por ridículo y ostentoso. Permítaseme observar tan solo, como botón de muestra de mis desvelos, que a veces he tenido que correr de una punta a otra de Londres sólo por fijar con la debida precisión una fecha, a sabiendas de que una vez lograda la máxima exactitud no me valdría ningún elogio, si bien un mínimo fallo en este sentido me habría desacreditado del todo».
} 
Historia del arte y las ideas estéticas del primer tercio del siglo XXI, de Juan Martín Prada (290-291), etc.

Asimismo, convergen en Fred Cabeza de Vaca numerosos puntos de vista. Junto a las notas autobiográficas, Natalia Santiago intercala con una tipología gráfica diferente (en cursiva) diecinueve comentarios, que tienen un papel destacado en la hermenéutica biográfica; en ellos -salvo una excepción, que contiene la respuesta dialógica al caos que impera en la clasificación archivística de la obra por parte del artista moraliano (246)- procura develar el significado de los textos autobiográficos con el fin de facilitar al lector la tarea de llenar los huecos de indeterminación. Cobran protagonismo en las glosas una multiplicidad de temas, como las referencias numéricas relativas a las relaciones afectivas de Fred (31); la caligrafía como criterio de datación cronológica en sus anotaciones (35); los proyectos artísticos realizados desde sus años universitarios (37); las condiciones fijadas por el artista en sus entrevistas (59); el machismo exacerbado que exhibe en sus diarios y la misoginia y objetuación y degradación de la mujer, incluida la de quien fue su única relación amorosa profunda: Gabriela Háfiz Cote (61); el oscurantismo de algunas prácticas habituales repulsivas, como la grabación a escondidas de los entrevistados (92) y las grabaciones de las mujeres con las que se acostaba, que custodia en su ordenador para subirlas a la plataforma de microbbling Tumblr (99); la ausencia de límites en el comportamiento sexual de quien asume con indiferencia "su nuevo estatus de sobjeto, de ente subjetivo cosificado en objeto» (111); la repercusión mediática que persigue con su arte, como la muestra de fotografías deslumbradas «Solaroids» (118); la red vista como un sosias inconsciente, que materializa como un doppelgänger los aspectos más sórdidos del ser humano (121); los móviles económicos de su actividad curatorial (144); las prácticas fraudulentas a través de las cuales conseguía muestras y subvenciones (260); los planteamientos mentales recurrentes del obsesivo artista, «cuyo efecto era retrotraerle a una cadena de ideas incesante, ad absurdum» (273) o el culto narcisista a la propia imagen con que se rinde tributo (283), entre otros.

Son muchísimos los intentos de la biógrafa por dejar constancia notarial de los hechos y exponer la información de la forma más exhaustiva posible, mostrando detalles referentes a la relación del biografiado con su madre, a sus motivaciones, miedos, fantasías y pulsiones. Natalia procede en su investigación con honestidad intelectual, sin censuras y sin 
eludir el carácter subversivo de una escritura biográfica, que no esconde los aspectos más viles y escandalosos del personaje; prosigue sus pesquisas con rigor al identificar las citas y fuentes utilizadas, distinguiendo entre estas y las aportaciones autobiográficas del personaje; incorpora la distinción que la cultura anglosajona introdujo entre biografías autorizadas y no autorizadas, como muestra la inserción de fragmentos de la biografía no autorizada de Freddy Cabeza de Vaca, titulada «Re$\operatorname{vol}(\mathrm{u}) \mathrm{c}(\mathrm{i})$ ones» (249-251) de Sara López Mencía, donde comenta una de las esculturas que presentó en una distópica Bienal de Pekín de 2025 y reflexiona sobre el ready-made a raíz de «ExCritura», de Fred:

La palabra escritura deriva del indoeuropeo skribh, que significaría corte o separación. Separar, discriminar, cortar, desbastar, seccionar, tajar, segregar, desviar, dividir, como forma de contar, de hilar aquello que parece disperso. La presente obra tiene por objeto refundir precisamente las partes escindidas por la narración del nosotros en una escultura del gran tamaño que procura la recuperación parmenideana del logos y, en consecuencia, la reconstrucción del sentido, en un mundo arrasado por la ruptura (249-250).

Nuevamente no debe confundir al lector el juego tensional que se plantea entre realidad y ficción en este esfuerzo biográfico. No estamos ante una biografía, pues este género se construye sobre personajes históricos, y no ficticios. Estamos ante la ficcionalización de un género literario, con el que invita a la reflexión metaliteraria. Llaman nuestra atención las palabras de Natalia Fermi referentes al modo en que se ha de relatar la vida y reflejar la identidad del biografiado:

Esqueje 8: ¿Cómo se cuenta una vida, cómo se destruye un relato existencial, cómo se levanta una biografía, con qué materiales? ¿Debe tender a la totalidad, debe detenerse sólo en los aspectos relevantes? ¿Debe ser un mosaico o una carretera? ¿Qué merece quedar dentro del recuento, y qué fuera de él? La biografía como relato de un relato(192).

Es un tema que está presente también en el intercambio de opiniones entre el artista Ramiro Mecamp y Natalia, donde subyace el dilema sobre el método biográfico:

Ramiro me ha dicho que la única manera de llegar a conocer a fondo la vida y la obra de un hombre muerto es biografiarlo. Creo que intenta 
decirme, de forma sibilina, que para no idealizar a Cabeza de Vaca debo ahondar en la parte existencial, puesto que al haberme centrado en su trabajo artístico tengo acceso a lo bueno de su persona, pero no a lo otro. [...].

Ramiro me recomienda que recabe testimonios sobre él, y sobre todo, que recopile y analice sus escritos, apuntes de diarios, fragmentos memorialísticos y demás huellas documentales, pues deben contener los únicos rastros de sí que dejó el artista (184).

Lo único que le importa a Natalia es lo específicamente artístico para estudiarlo con rigor, contemplarlo como un objeto que se basta a sí mismo, autosuficiente y coherente, al entender que el significado de la obra no tiene nada que ver con la biografía del autor. Se enfrenta así a la reclamación de Ramiro quien, convencido como Sainte-Beuve de que la biografía ilumina la obra, concibe que cualquier lenguaje manifiesta y refleja la vida del artista. Subyace nuevamente la cuestión de la falacia biográfica, una de las cuatro que sistematizó el New Criticism. Ya a comienzos de siglo XX Marcel Proust sostuvo en Contra Sainte-Beuve que el laureado crítico francés no había comprendido «lo que la inspiración y el trabajo literario tienen de específico, y lo que le diferencia completamente de las ocupaciones de los demás hombres y de las otras ocupaciones del escritor» (Proust, 2004: 65).

Adquiere significado en este marco el documento "[ac. Res4556]», que contiene una triple escritura anafórica con los tres borradores de la respuesta de Fred a una de las preguntas de Eckermann, donde reiteradamente se repite:

Uno de los mayores errores críticos que pueden cometerse es la «falacia biográfica»: pensar que las obras artísticas vienen impulsadas siempre por vivencias personales del autor, o por resortes secretos de su periplo vital o afectivo. Nunca me han interesado las interpretaciones psicoanalíticas o psicobiográficas, ya sean de otros hacia otros, ya sean de otros hacia mí. La filosofía me ha protegido siempre de esas zarandajas esotéricas [...] (119).

Fred sale así al paso del error crítico que se deriva de subrayar la repercusión que tienen en su obra artística la infancia y la relación con su madre: 
Es como un vacío absoluto que no hubiese dejado rastro alguno, un agujero negro que elimina cualquier huella de la energía en torno. Intento comportarme como si jamás hubiese existido y yo hubiera surgido de mi propia cabeza, en una especie de Bing Bang, o de Big Gang Band. Ella es un cero a la izquierda de mi vida: desde hace muchísimos años soy el único dueño de mis actos y de mi propio destino (119).

Y pretende, asimismo, legitimar la interpretación que de su vida y obra hace la biógrafa N. S. Fermi: «Mis obras nacen de una voluntad consciente y madura, que no debe nada a nadie más que a mí mismo en el momento actual. No hay recados ni rémoras, ni ajuste de cuentas con respecto al pasado» (119).

En sus apuntes biográficos arroja a través de numerosos recovecos su personalidad y una inmensidad de historias, que parecen reales y no lo son, creando una extraña cualidad ilusoria. No extraña por tratarse de la obra de un autor que considera que «los sujetos somos ficción» o constituimos "la realidad que somos a partir de un proceso ficcional, de un storytelling que nos construimos a voluntad -y quizá a nuestra plausible imagen y semejanza-» (Mora, 2009)6.

Con Fred Cabeza de Vaca el escritor muestra interés por hallar una nueva forma expresiva, que sea esencialmente una pregunta sobre las posibilidades de la ficción para emprender la representación del mundo actual. La novela interpela, conjura e interroga de manera sostenida al texto y lo convierte en un espacio de metalectura sobre el estatuto de la obra literaria. El texto, y solo el texto, interesa. La obra es, antes que nada, un objeto de dominio público y no la creación privada de un individuo, de modo que tanto la experiencia del autor como su intención en el momento de la escritura carecen del más mínimo interés. Desde la subversión de la práctica artística la novela es una defensa de la imaginación como disidencia. El escritor despliega un juego de posibilidades ilimitadas de construir la realidad y de comprender la práctica artística con inmensa libertad poético-literaria; así, con la yuxtaposición de diferentes niveles discursivos y tejidos textuales, con la multiplicidad de

${ }^{6}$ Así lo sostuvo en la defensa de la tesis doctoral El yo penúltimo. Subjetividad y espejo en la literatura española de la postmodernidad (1978-2008), publicada después (Mora, 2016). 
perspectivas y ángulos desde los que observa la realidad, y con la provocación permanente trastorna al lector.

Sin precedentes ni esquematismos previos ahonda narrativamente en la contemplación de la realidad como un work in progress, que se construye en un proceso de mutación continuada. La biógrafa abandona el proyecto y manda a Ramiro el material que el lector tiene en su poder con la siguiente aclaración: «ni ella ni yo nos hemos atrevido a montar las piezas, esto es, a crear con esta selva documental algo parecido a un libro» (314). A esta perspectiva responde tanto la propia vida del personaje que protagoniza la obra como la pretensión fallida de reconstruir su biografía por parte de Natalia, como consignan las palabras de Mecamp:

Como puedes imaginar, querido E., os espera un complejo trabajo para ordenar toda esta vorágine y que tenga sentido. El conjunto, tal y como está ahora reunido, es impublicable; no sólo por razones textuales, sino también éticas y aún jurídicas, pues algunos de los insertos tendrían, tal y como están en este instante recogidos, consecuencias legales para la editorial y legales y personales para Natalia, pero ella no se sentía con ganas de volver al conjunto para quitar algunas páginas. Prefiere pensar que lo haréis vosotros. [...] Pero me parece loable que intentes por vía editorial conformar o trazar un bosquejo, un boceto, unos esbozos, de lo que fue Fred (316).

\section{COMPOSICIÓN BIOGRAFEMÁTICA Y ESTÉTICA DE LA OCULTACIÓN Y DE LA INSUFICIENCIA}

Si yo fuera escritor y estuviera muerto, me agradaría que mi vida se redujera mediante los cuidados de un biógrafo amistoso y desenvuelto a algunos detalles, a algunos gustos, a algunas inflexiones, digamos a algunos 'biografemas' cuya distinción y movilidad pudieran trasladarse fuera de todo destino y llegar a tocar, cómo átomos epicúreos, algún cuerpo futuro, destinado a la misma dispersión; en suma, una vida abierta en brecha, así como Proust supo escribir la suya en su obra (Barthes, 1989: 11).

Las palabras de Roland Barthes nos introducen en la cuestión biográfica como el recuento de una vida. La biógrafa, siguiendo la concepción barthesiana del biografema como aquello que se escribe de la persona a 
quien se $\mathrm{ama}^{7}$, reprocesa los momentos vivenciados y almacenados en la memoria del artista y los recopila de manera fragmentaria:

[Comentario] [El fragmento intermedio es relevante porque delata que Fred, consciente de su celebridad artística, daba por supuesto que algún día sus diarios iban a ser leídos. Están escritos para sí, pero con un ojo puesto en los otros, como esos adolescentes que posan al moverse, pensando que alguien graba y analiza todas sus acciones] (283).

Así lo expuso el semiólogo francés cuando afirmó: «Escribir por fragmentos: los fragmentos son entonces las piedras sobre el borde del círculo: me explayo en redondo: todo mi pequeño universo está hecho migajas: en el centro, ¿qué?»(Barthes, 1997: 104). Tanto Fred como Natalia abogan por la fragmentación. La biógrafa lo hace con el fin de dotar de significado a cada biografema dentro de un todo narrativo articulado, siguiendo el método que propuso Magris (1999: 29), como señala en el primer esqueje, donde inserta íntegramente un fragmento del mismo:

Si una biografía aparece rota en pedazos, cada uno de estos pedazos posee, en mayor medida aún, una realidad propia indeleble. Una realidad que seguramente se perdería si el fragmento fuese simplemente integrado, como un ladrillo, en el armonioso edificio de una biografía tradicional (184).

Asimismo, la infinidad de archivos y de perspectivas que presentan los escritos biográficos del artista son una invitación a que el lector entable un diálogo inconcluso con el discurso de un personaje que se presenta como un ser inasible. Fred, larvario y variable, se encuentra sumergido en experiencias que configuran su disociación, como se deduce de uno de los comentarios de naturaleza especular, donde Natalia refleja la vida de un individuo carente de escrúpulos:

[Comentario] Lo repulsivo del comportamiento de Fred no estriba tanto en su bajeza trepadora, ni en su necesidad de protagonismo, ni en su ahorro de cualquier clase de vergüenza, ni siquiera en su capacidad de

${ }^{7}$ Afirma Barthes (1989: 62): «La Fotografía me permite el acceso a un infra-saber; me proporciona una colección de objetos parciales y puede deleitar cierto fetichismo que hay en mí: pues hay 'yo' que ama el saber, que siente hacia él como un gusto amoroso. Del mismo modo, me gustan ciertos rasgos biográficos en la vida de un escritor me encantan igual que ciertas fotografías; a estos rasgos los he llamado 'biografemas'; la Fotografía es a la Historia lo que el biografema es a la biografía». 
prostituirse sexualmente para lograr lo que desea. Su nuevo estatus de puto no le supone ningún reparo moral o ético. Lo detestable no radica en la asunción indiferente de su nuevo estatus de sobjeto, de ente subjetivo cosificado, convertido en objeto. [...]

La contabilidad como eje de la experiencia amorosa, la acumulación capitalista de seducciones, la sexualidad como otra forma de consumo desaforada, el prestigio construido sobre resultados anuales (112).

Fred es, como el Ulrich de Musil, un hombre sin atributos, que vive un presente sin solución de continuidad, sin dirección ni sentido, y que compulsivamente se explora mientras registra su ego autoescindido. Este resquebrajamiento identitario alcanza su culmen en uno de sus últimos proyectos artísticos que -según precisa la biógrafa- no llegó a cuajar: la creación de una «lengua de la negatividad», es decir, «un registro lingüístico acotado a la expresión del dolor y de la angustia, un habla negra, dialéctica con el idioma tradicional» (286). Esta habla negra se visualiza en un artículo que Fred publicó en Eñe, del que ofrecemos esta cita:

Transporto el orco conmigo. Su voz es chamariz de otras acedías y daños, convocados al trayecto dextrorso de la kathabasis; aután bogando al origen en su ciar, penosa es la hégira y valetudinario el viajero, temulentos los sosias etarios y compañeros vómicos por el hámago pertinaz ante el canope, acaso anhelas ocelos de escape para ver desde arriba la isoclina (288).

Fred Cabeza de Vaca es un instrumento de exploración de la realidad en el que se reflejan las tensiones existentes entre el orden real y simbólico. La negatividad y el vacío se presentan como modalidades de la realidad y motores de la creación artística. Para quien considera que toda manifestación artística es «el resultado sobre una mesa de operaciones técnicas» (Mora, 2017b), que reside en el manejo de la estructura narrativa y del lenguaje, Fred Cabeza de Vaca constituye un alarde de inventiva, de disección de la mítica identidad del yo y un medio de expresión de la estética de la insuficiencia y de la ocultación.

El lector se enfrenta a una novela egódica, que aborda el exceso en el tratamiento de la identidad y ahonda en la realidad poliédrica del sujeto contemporáneo, de un "ego excesivo, sobredimensionado o hinchado» (Mora, 2013: 13). Es, asimismo, una novela experimental en la que prima 
la técnica de la ruptura desde múltiples perspectivas: la alteración de la secuencia temporal, de la representación referencial, del continuum discursivo, etc. La fragmentariedad y el hermetismo están al servicio de la representación de una unidad interrogante, donde los acontecimientos narrados lejos de ser «episodios de una serie, inteligibles como piezas de un todo» (Calvo, 2010: 12) ceden espacio a la difícil interpretación, según muestra Natalia en diferentes ocasiones a lo largo de su trabajo:

[Comentario] [Imposible identificar el interlocutor de la conversación; no se ha encontrado la grabación original y el documento de Word que recoge la conversación fue creado en 2018, año en el que Fred comisarió hasta tres exposiciones ligadas a algunas grandes instituciones o bancos] (92).

La composición biografemática de Fred Cabeza de Vaca visibiliza las relaciones existentes entre los fragmentos y subraya los esfuerzos hermenéuticos emprendidos por Natalia para descifrar el enigma que se oculta tras la actuación narcisista del artista:

Comienzo a darme cuenta de muchas facetas de Fred que, hasta hace apenas unos meses, jamás hubiera sospechado. Hilos escindidos por diversas personas por separado, pero que soy la primera en tejer. Detalles, hechos, gestos que harán cambiar su imagen pública. O que la asentarán, quién sabe (64).

Natalia que, como diría Barthes (1975: 172), «pone y quita comillas con presteza...se pone a escribir conmigo», es la nueva Penélope que teje esforzadamente el tapiz biográfico.

Asiste el lector a una doble lectura; en primer lugar, a la comprensión de la cosmovisión del mundo de Fred (a través de la narración propia y ajena con la complejidad dramática que estas entrañan), quien atisba un mundo convulso, que se transforma en un pozo sin fondo e incognoscible, como refleja en su diario:

La realidad me parece incognoscible, una suma de fenómenos desmembrados. Voy por la calle con los ojos abiertos, pero no entiendo nada. Es como si estuviera ciego, aunque puedo ver. Nada me resulta descifrable. Todo me sorprende y parece regido por una lógica que no comprendo. De modo que no me sirve de nada la vista. Soy un invidente funcional. 
Todo acontece para otros, o para otra dimensión, o en otras coordenadas.

Lo que tengo antes mis ojos no es significativo, no habla (34).

Y, en segundo lugar, asiste a la lectura de las impresiones y reflexiones de Natalia, quien vertebra un mosaico narrativo, mientras intenta compilar y ordenar las múltiples piezas dispersas que conforman su proyecto cuasi-policíaco, y contempla la vida de un ser a la deriva, escindido y con los fundamentos de su identidad y pertenencia desmoronados. Como vemos, desde la fragmentariedad discursiva y narratológica el escritor proyecta la crisis y disolución del yo contemporáneo, la desgarradora conciencia atomizada de lo múltiple y la indescifrabilidad de lo real.

La escritura fragmentaria de Fred con sus permanentes quiebras discursivas permite que sean otros, los biógrafos, los críticos o los lectores, quienes lo hagan. El encabalgamiento de los lenguajes fragmentarios es propuesto como placer del texto y placer de la lectura, que escapa a la representación y dificulta la comprensión del sujeto. Fred Cabeza de Vaca plantea una escritura desgajada del todo, que proyecta como en un espejo el desgarro y fractura interiores del artista, y el extrañamiento que suscita el sujeto contemplado desde la alteridad. Siguiendo la tesis de Barthes (1997: 23) sobre la imposibilidad de reducir la escritura a una única voz pues es una recopilación infinita de discursos y citas que obligan a que el escritor regrese a una escritura anterior, pesa sobre el lector la responsabilidad de conceder un sentido al texto que se le ofrece.

Fred Cabeza de Vaca se configura como un proyecto colectivo de escritura, donde adquiere relevancia la apertura del constructo narrativo; como en el arte conceptual, lo esencial no es tanto la ejecución plásticoartística como el desarrollo teórico de la idea. La novela funciona, en consecuencia, como una máquina narrativa abstracta, configurada por múltiples formas discursivas y códigos artístico-semióticos perfectamente ensamblados, para mostrar que todo enunciado «es siempre colectivo, incluso cuando parece haber sido emitido por una singularidad solitaria como la del artista» (Deleuze y Guattari, 1980).

Lejos de estar ante un proyecto narrativo agotado que no contiene nada nuevo, el autor despliega en esta obra diversas representaciones de la identidad del sujeto -incluida la identidad virtual (correo electrónico, blog, chat)- a través de los residuos y basuras textuales, «que se resuelven en un mismo flujo que conjuga informaciones, ficciones, invenciones, 
documentos y disfraces» (Ladagga, 2007: 20); mediante esta imagen metafórica y a través de la disolución de las fronteras entre sujetos y objetos proyecta la visión del mundo como un continuum de partículas agregadas que unifica los cuerpos y los desintegra, y emprende una indagación sobre la realidad ${ }^{8}$ :

[3.oo a.m.] La gente ama la basura porque es su rostro, es la manera de determinar que están vivos y la estela de sus quehaceres. Es el rastro de su consumo. Es la huella de que han podido gastar y han gastado, de que han podido comer y han comido, de que incluso han podido derrochar, crear desperdicios, tirar las sobras. Y la basura es también un nuevo objeto creado: la cerrar la bolsa negar con lazos de plástico coloreado se logra un ente estético: perfecto, inodoro, regordete, bien cerrado, brillante como un regalo envuelto con lacito para entregar en mano (195).

Frente a la visualidad que impone la globalidad con la proliferación desmedida de imágenes, defiende el artista la «suspensión de la enunciación» (Martín Prada, 2012: 137) y la irrupción de la imaginación que no se agota en el proceso del mirar y requiere la implicación activa del receptor, como postula Marcel Duchamp en $\dot{A}$ bruit secret, que solo adquiere sentido con la acción del espectador. Desde este prisma adquieren significación las tesis de Fred sobre el borrado de la imagen y la estética de la ocultación, que estuvo presente en el inquietante y provocador imaginario fotográfico de Guy Bourdin (96) con su forma peculiar de cuestionar tabúes, o en la novela inacabada Le mont analogue, de René Daumal, ambos mencionados en «Transcripción parcial de una mesa redonda con participación de Cabeza de Vaca: Universidad de Autónoma de Madrid, 15/05/2017»:

$\mathrm{El}$ arte es euclidiano por naturaleza, es una especie de realidad tetradimensional cuya cuarta pared -el tiempo- altera la percepción y la fenomenología del gusto. «Estamos», decía Novalis, «más estrechamente ligados a lo invisible que a lo visible», y lo que somos está en lo que no vemos de nosotros mismos, aquello que está dentro de la mente y que es, por naturaleza, tan sensible de sentir como imposible de ver (96).

${ }^{8}$ Cobra relieve «Pensar sobre el cerebro», artículo que publica Fred en Jot Down, donde alude a la creación del Ministerio de la Basura y de la unidad ministerial de Reciclaje Medial y Artístico (251-252). 
Más allá del intento de hacer visible lo invisible, invita Mora con Fred Cabeza de Vaca a abandonar toda convención categórica y a cultivar una mirada que, más allá de la sobreexposición a lo sensorial, se adentre en la producción de sentido y en los juegos del lenguaje, según las tesis de Bachelard: «Si no hay cambio de imágenes, unión inesperada de imágenes, no hay imaginación, no hay acción imaginante» (9).

Desde que la totalidad fue considerada como una noción «cerrada», a partir de Nietzsche fue puesta en sospecha y concebida como una realidad abierta que no puede ser fundamento de lo real, y Blanchot (1973) defendió la lógica del fragmento que se desembaraza del todo para desplazar la lógica homogénea. A pesar de que la posmodernidad ha potenciado la sospecha de que la realidad es un simulacro, la ficción, más allá de hacer referencia a la verdad o falsedad de la referencialidad discursiva o de distinguirse por sus peculiaridades formales o mecanismos dispositivos narrativos, sobresale por la capacidad para alzar un mundo imaginario autónomo y verosímil, que se presenta como tal a la interpretación del lector.

Subyacen así en Fred Cabeza de Vaca algunas de las tesis que han alcanzado más desarrollo con la posmodernidad. A partir de la negación de la posibilidad del acceso epistemológico a la realidad, de la supremacía de la forma de transmisión de la obra de arte sobre el contenido y de la consideración de que toda mímesis artística es el resultado de la interpretación subjetiva, la obra explora los límites referenciales del discurso literario e indaga sobre la posibilidad de transmitir un universo ficcional a través de formas expresivas propias de la no-ficción, invirtiendo los espacios referenciales y epistemológicos configuradores de cada género. Con agudeza intelectual y brillantez estilística, Vicente Luis Mora muestra su pericia en la técnica novelística de un work in progress, que se resiste a la clasificación y al deslinde entre fronteras estéticas y exhibe un proceso creativo abierto, donde el collage narrativo se halla al servicio de la concepción del arte como proceso inconcluso que perturba al lector.

Con la complejidad y el enigma que vertebran la obra, el escritor devuelve la mirada del lector al territorio de la imaginación y de la abstracción; a pesar de los intentos de Fred por dejar constancia de su realidad y por exhibir su condición de artista, mediante la sustracción de la transparencia provoca la interrupción de lo convencional e invita al lector a 
abrir espacios ficticios abiertos, como la interpretación de los ruidos (Baudrillard y Calabrese, 2014: 40):

Madrid temblaba las primeras mañanas del siglo 21, sacudida por el incesante ruido que venía de las toses, de los chirridos de las ruedas de los coches, del estruendo de los cláxones, de los altavoces publicitarios, de los rings de las bicicletas, de la barahúnda de los gritos de los vendedores ambulantes, de los balones de los niños contra el suelo, de los chorros de agua rompiendo contra las fuentes (33-34).

De manera explícita, con la reescritura de la imagen de honda intertextualidad shakespeariana «mucho ruido y no pocas heces» condensa el vacío y la angustia imperantes; y establece una red de conexiones entre la identidad del individuo, quienes pueblan su universo existencial y la sociedad desarticulada que lo acoge con su cacofonía y ruido incesantes. Con una multiplicidad de elementos fragmentarios, Fred Cabeza de Vaca alza una historia individual y generacional, confronta al lector con la memoria privada y pública y apela a la ética del individuo, del trabajo, de la convivencia y de las relaciones humanas y a una ética del sistema social; muestra, en suma, la vigencia de la literatura como instrumento de conocimiento de la contemporaneidad y de indagación distópica.

Provocativamente se nos muestra todo en un proyecto biográfico que nace con el imperativo de recoger toda la información que vierte un artista que no guarda espacios de intimidad y banaliza su existencia con la sobreexposición del cuerpo. Y, sin embargo, el trompe-l'œil que esconde el afán exhibicionista de Fred es un recurso para despertar la mirada decepcionada de nuestros tiempos a través de las sombras de la luna y del territorio enigmático que la obra plantea y que el lector ha de desvelar (Brea, 1996: 5) ${ }^{9}$.

${ }^{9}$ Aunque no es el momento de emprender esta investigación, sería interesante estudiar la relación que se establece entre la sobresaturación, el excesivo ruido, la hegemonía de la visualización, la hipervisibilidad y la sobreexposición en nuestra sociedad contemporánea con la potencialidad de la obra artística velada, siguiendo las tesis de Reguera (2008). 


\section{CONCLUSIONES}

En Fred Cabeza de Vaca a través de una narrativa circular y especular configura una visión de la ficción que interpela la esencia de lo real. Con una propuesta narrativa compleja en su significado, estructura y configuración genérica, con un vasto caudal de erudición, con un brillante despliegue de la ironía y con el cuestionamiento de la dicotomía teoríapráctica, Vicente Luis Mora deja que sea el lector quien interprete las claves interpretativas de la obra. Queda en sus manos decidir si Fred Cabeza de Vaca fracasa en su intento de liberar al artista de los corsés y de las ataduras del lenguaje y de hacer de la propia vida una obra de arte; y si triunfa o no en el intento de dar la espalda al imperativo vigente de decirlo o mostrarlo todo para devolver la mirada al terreno de la imaginación, conquistar la interioridad como espacio privado y crear un espacio abierto -siguiendo a Eco (1962)- de interpretación y de pensamiento mediante una poética de la ocultación.

\section{BIBLIOGRAFÍA CITADA}

Albaladejo, T. (1992): Semántica de la narración: la ficción realista. Madrid: Taurus.

Alberca, M. (2017): «La extinción del arte». Letras Libres, 44-45 (en línea: <www.letraslibres.com/mexico/libros/la-extincion-del-arte>, consulta: 17 de septiembre de 2020).

ÁLVAREZ, M. A. (1989): «La autobiografía y sus géneros afines». Epos, 5, 439-450.

BAQUERO EsCUDERO, A. L. (2007-2008): «Un viejo y persistente tópico literario:

el manuscrito hallado». Estudios románicos, 16-17, 249-260.

BARTHES, R. (1975): $S / Z$. New York: Hill and Wang.

BARTHES, R. (1989): La cámara lúcida. Madrid: Paidós.

BARTHES, R. (1997): Roland Barthes por Roland Barthes. Caracas: Monte Ávila. BAUdRILlard, J. y CALABRESE, O. (2014): El trompe-l'oeil. Madrid: Casemiro.

BlANCHOt, M. (1973): Nietzsche y la escritura fragmentaria. Buenos Aires: Cálden. Boswell, J. (2007): Vida de Samuel Johnson. Barcelona: Acantilado.

BREA, J. L. (1996): Un ruido secreto: el arte en la era póstuma de la cultura. Murcia: Mestizo.

CABALlÉ, A. (1995): Narcisos de tinta. Ensayo sobre la literatura autobiográfica en lengua castellana. Madrid: Megazull. 
Caballé, A. (2012): "¿Cómo se escribe una biografía». Rubrica Contemporanea, 1.2, 39-45 (https://doi.org/10.5565/rev/rubrica.28).

CAlvo, J. (2010): «La red siniestra». Quimera, 318, 12-17.

Deleuze, G. y GuAtTARI, F. (1980): Kafka. Para una literatura menor. México: Era.

Deleuze, G. y Guattari, F. (1997): Mil mesetas. Capitalismo y esquizofrenia 2. Valencia: Pre-textos ( $3^{\mathrm{a}}$ ed.).

Eco, U. (1962): Obra abierta: forma e indeterminación en el arte contemporáneo. Barcelona: Seix Barral.

García GuAL, C. (2002): Apología de la novela histórica y otros ensayos, Barcelona: Península.

LADAGGA, R. (2007): Espectáculos de realidad. Ensayo sobre la narrativa latinoamericana de las últimas dos décadas. Rosario: Beatriz Viterbo.

LeJeune, Ph. (1971): L'aulobiographie en France. Paris: Armand Colin.

MAGRIS, C. (1999): «Biografía y novela». Revista de Occidente, 220, 21-37.

Martín Prada, J. (2012): Otro tiempo para el arte. Cuestiones y comentarios sobre el arte actual. Valencia: Sendemà.

MorA, V. L. (2008): “Colverfield, Ana Merino, Lolita Bosch, Fernández Buey». Blog Diario de lecturas (en línea: <http://vicenteluismora.blogspot.com/ 2008/01/cloverfield-ana-merino-lolita-bosch.html>, consulta: 10 de febrero de 2021).

MoRA, V. L. (2009): «Defensa». Blog Diario de lecturas (en línea: <http://vicenteluismora.blogspot.com/2009/06/defensa.html>, consulta: 10 de febrero de 2021).

Mora, V. L. (2010): Quimera, 322, septiembre ${ }^{10}$.

MoRA, V. L. (2013): La literatura egódica. El sujeto narrativo a través del espejo. Valladolid: Universidad de Valladolid.

Mora, V. L. (2016): El sujeto boscoso. Tipologías subjetivas de la poesía española contemporánea entre el espejo y la notredad (1978-2015). Madrid: Iberoamericana/Vervuert.

Mora, V. L. (2017a): Fred Cabeza de Vaca. México: Sexto Piso.

MoRA, V. L. (2017b): «Entrevista a Vicente Luis Mora, de Esther Peña». La Galla Ciencia (en línea: <http://lagallacienciaestherpenyas.blogspot.com/2017/11/ entrevista-vicente-luis-mora.html>, consulta: 10 de febrero de 2021).

Pozuelo Yvancos, J. M. (1993): Poética de la ficción. Madrid: Síntesis.

\footnotetext{
${ }^{10}$ Monográfico de la revista, redactado íntegramente por el escritor, inventándose firmas apócrifas.
} 
Proust, M. (2004): Contra Sainte-Beuve. San Lorenzo del Escorial: Landre.

REGUERA, G. (2008): La cara oculta de la luna. En torno a la «obra velada»: idea y ocultación de la practica artística. Murcia: Cendeac.

WimSaTt, W. K. (1954): The Verbal Icon: Studies in the Meaning of Poetry. Lexington: University of Kentucky Press.

Ana CALVo ReVILLA

Universidad San Pablo-CEU

crevilla.ihum@ceu.es

https://orcid.org/0000-0002-0286-5767 
